\title{
CUTANEOUS MYIASIS DUE TO CUTEREBRA IN MASSACHUSETTS
}

\author{
By J. Bequaert
}

Museum of Comparative Zoölogy, Cambridge, Mass.

The Tumor Diagnosis Service of the Harvard Medical School recently referred to me a large maggot said to have been removed from the human skin. It was readily recognized as a bot-fly larva of the genus Cuterebra. As there appears to be no previous record of a bot of this type causing cutaneous myiasis in man, some further inquiry was made about this case.

Dr. Rene B. LeClair, of Ware, Massachusetts, who sent in the specimen, upon my request gave the following information with kind permission to use it in print. The maggot was extracted by Dr. LeClair in September, 1945, from the skin of a male resident of Ware. It was located about two inches below the right nipple in what was thought at first to be a furoncle. The posterior spiracles of the maggot showed, however, like a "black head" through an opening in the center of the swelling. The maggot was fully alive after removal. As now preserved in alcohol, it is $15 \mathrm{~mm}$. long, $8 \mathrm{~mm}$. wide and $6 \mathrm{~mm}$. thick. The patient's living conditions are described as of a very low order, as he is more often drunk than sober. This may give a clue as to how the unusual infection was acquired.

The genus Cuterebra is restricted to the New World, where it is represented by many species attacking a variety of wild mammalian hosts and occasionally certain domestic animals. ${ }^{1}$ Three species are definitely known to occur in New England, and more particularly in Massachusetts. While the specific larval characters of most species are as yet imperfectly known, this is fortunately not the case for our three local species. These may be readily separated by means of the descriptions and figures recently published by E. F. Knipling and A. L. Brody (1940, Jl. of Parasitology, XXVI, pp. 33-43, 2 Pls.). The human maggot of Ware shows all the characteristic features of

\footnotetext{
${ }^{1}$ The generic name Cuterebra is here used in the broad sense, to include Bogeria and several other groups which have been separated from it in recent years.
} 
the third instar of Cuterebra buccata (Fabricius) and I do not hesitate in referring it to this species. The posterior spiracular plates are shaped as in Knipling and Brody's Pl. I, fig. 2; while the spines, which cover the body fairly uniformly, are as shown in their Pl. II, fig. 9, with simple, sharp, moderately long, slanting points. The normal larval hosts of C. buccata are wild and domestic rabbits, in which animals the mature third instar maggot reaches 26 to $32 \mathrm{~mm}$. in length, so that the larva removed from man was about half-grown.

In tropical America the maggot of the genus Dermatobia, a relative of Cuterebra, common in many types of mammals, has often been observed attacking man. A careful canvassing of the literature has, however, failed to disclose a previous case of human cutaneous myiasis due to Cuterebra either in North or in South America. F. C. Bishopp (1942, Proc. Ent. Soc. Washington, XLIV, p. 15) reported that a first instar maggot of an unidentified species of Cuterebra was removed from the nostrils of a person in Arlington Co., Virginia. This human case was also discussed by R. G. Beachley and F. C. Bishopp (1942, Virginia Med. Monthly, LXIX, pp. 41-42). 

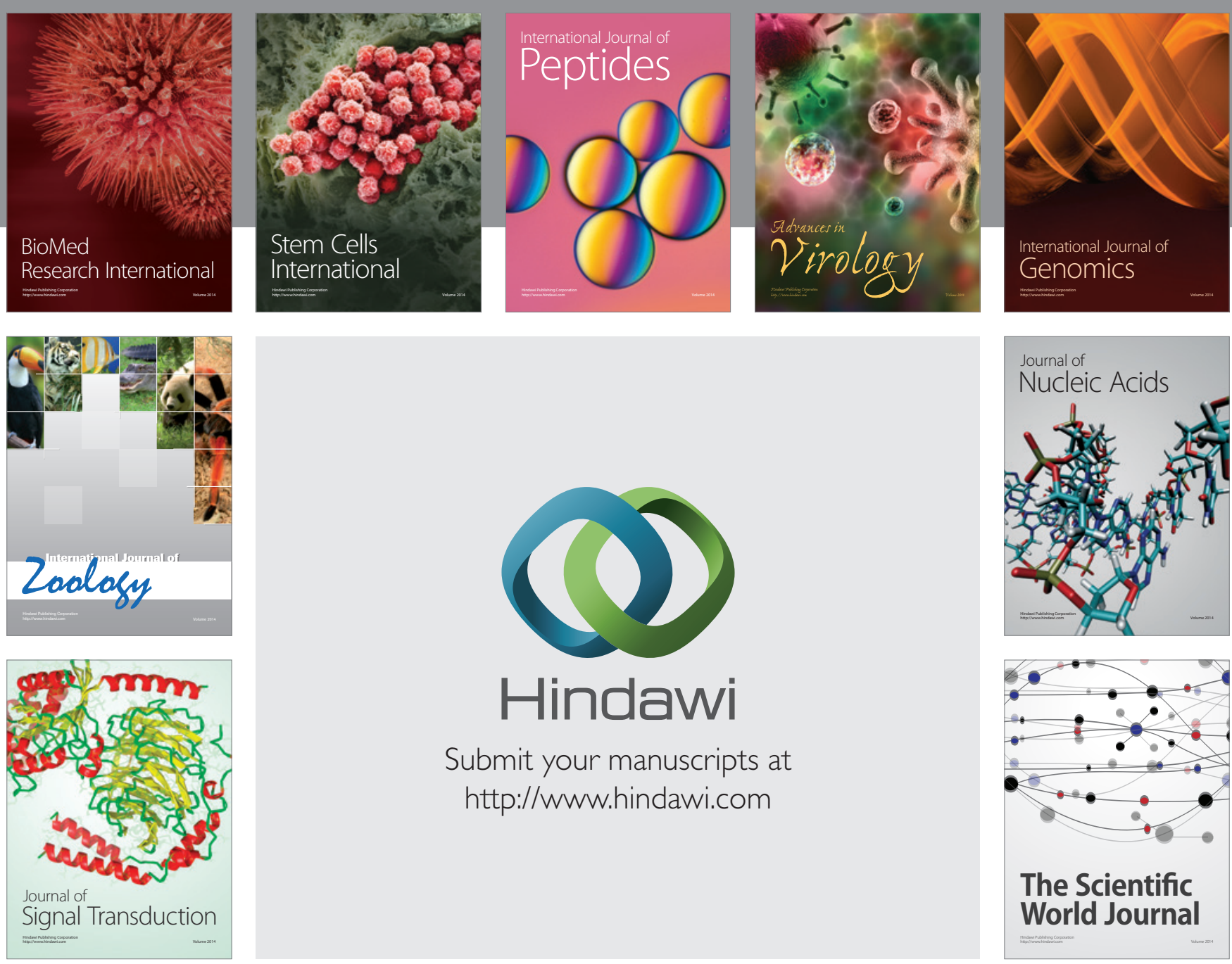

Submit your manuscripts at

http://www.hindawi.com
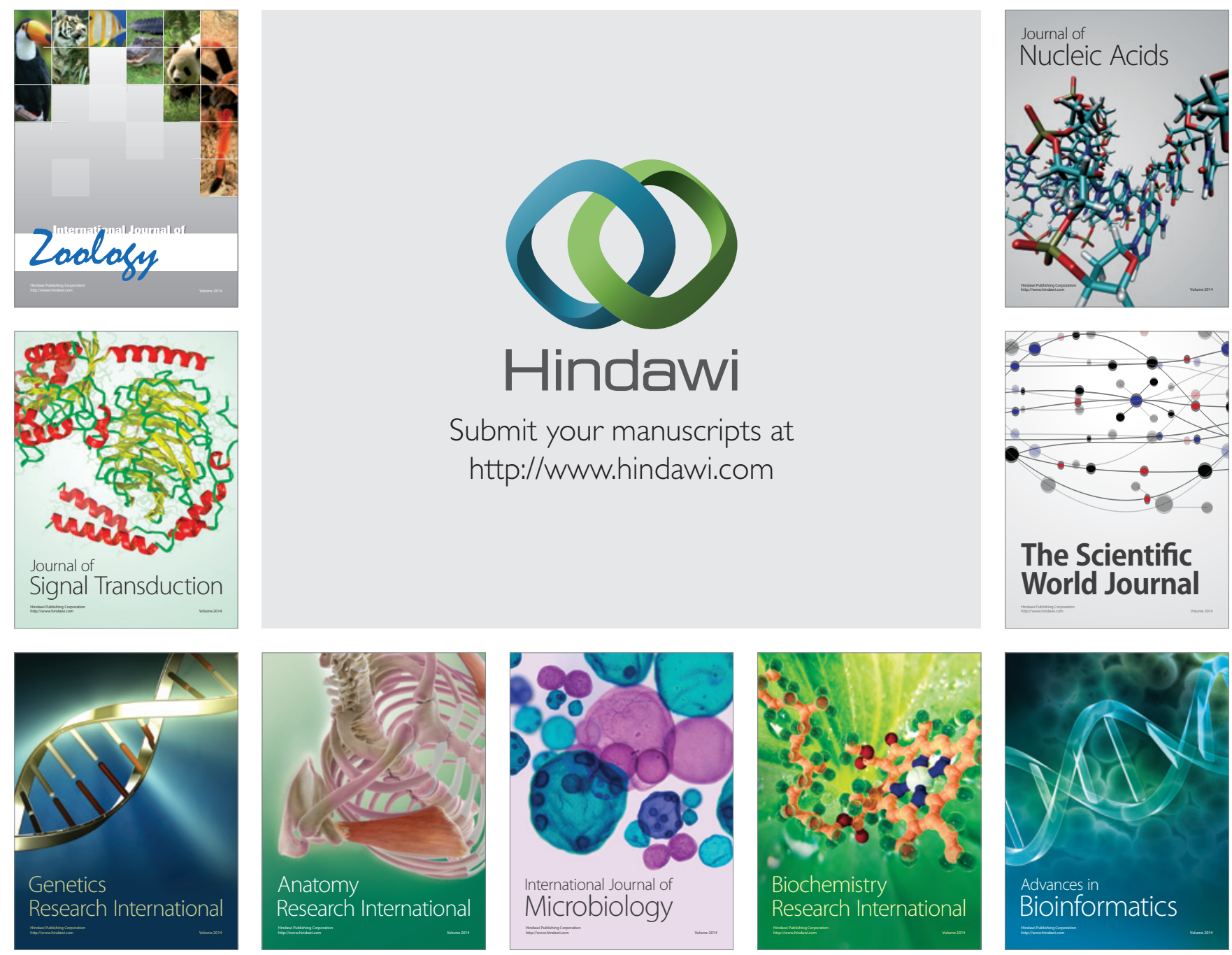

The Scientific World Journal
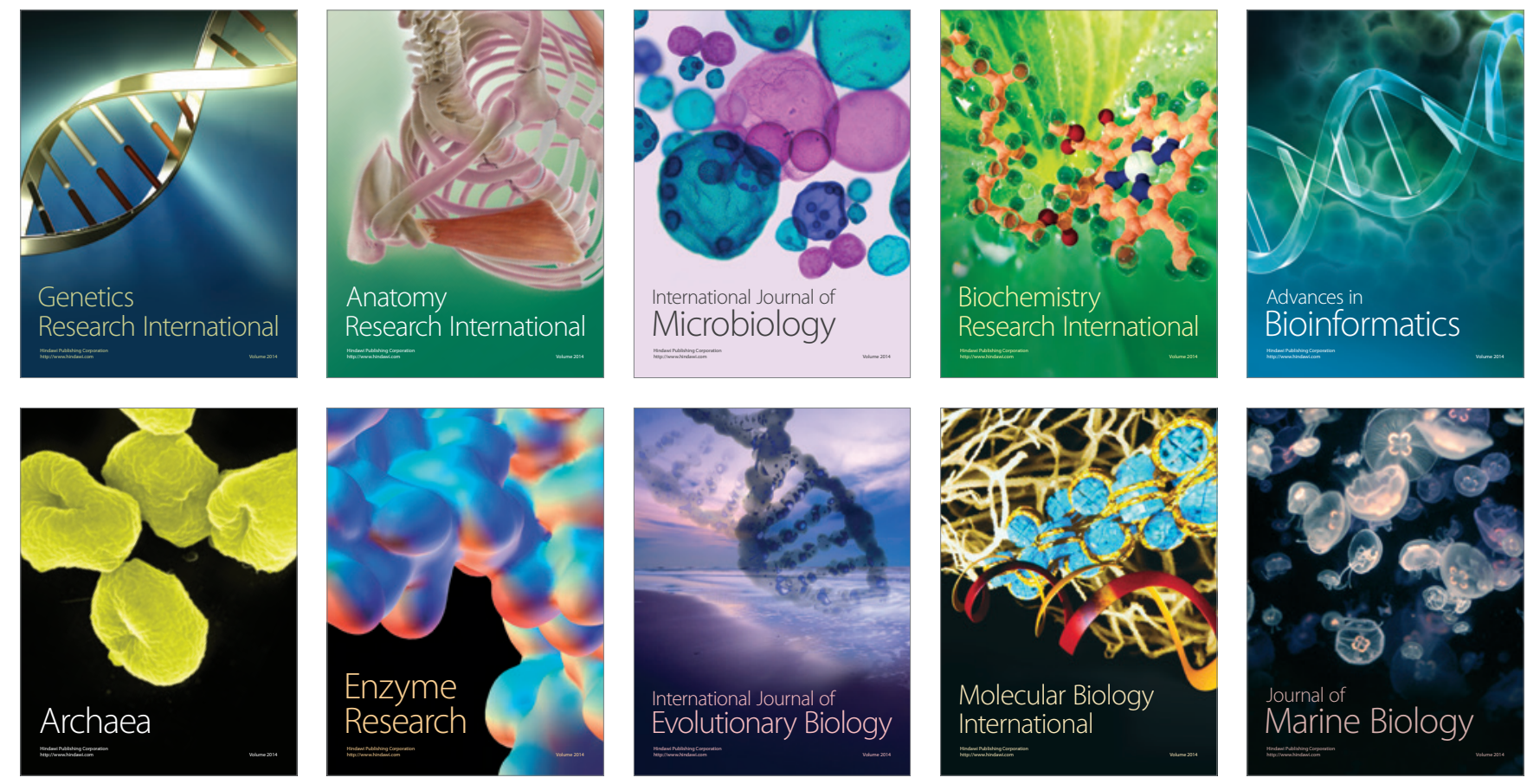